\title{
PANDA: A Multipurpose Integral Test Facility for LWR Safety Investigations
}

\author{
Domenico Paladino and Jörg Dreier \\ Nuclear Energy and Safety Research Department, Paul Scherrer Institut (PSI), 5232 Villigen, Switzerland \\ Correspondence should be addressed to Domenico Paladino, domenico.paladino@psi.ch
}

Received 18 April 2011; Accepted 25 August 2011

Academic Editor: Klaus Umminger

Copyright ( $) 2012$ D. Paladino and J. Dreier. This is an open access article distributed under the Creative Commons Attribution License, which permits unrestricted use, distribution, and reproduction in any medium, provided the original work is properly cited.

The PANDA facility is a large scale, multicompartmental thermal hydraulic facility suited for investigations related to the safety of current and advanced LWRs. The facility is multipurpose, and the applications cover integral containment response tests, component tests, primary system tests, and separate effect tests. Experimental investigations carried on in the PANDA facility have been embedded in international projects, most of which under the auspices of the EU and OECD and with the support of a large number of organizations (regulatory bodies, technical dupport organizations, national laboratories, electric utilities, industries) worldwide. The paper provides an overview of the research programs performed in the PANDA facility in relation to BWR containment systems and those planned for PWR containment systems.

\section{Introduction}

The research programs performed in the PANDA facility are devoted to improving safety and economics of current (Generation II) as well as more advanced (Generation III) LWR types.

Past and ongoing programs performed in PANDA are listed in Table 1, while photos of the PANDA facility are shown in Figure 1. In Table 1, the project investigating LWR containment is marked in grey, whereas projects devoted to produce data on separate effects with high safety relevance are marked in white. The facility has been initially built and used in a consortium between PSI and (Electric Power Research Institute) EPRI/(General Electric) GE to study the passive decay heat removal systems and containment response for the Simplified boiling water reactor (SBWR). Later the PANDA facility was used for investigations related to the (passive containment cooling system) PCCS of the ESBWR (Economic/European SBWR) (Figure 2, Section 3.2) in the framework of the European Union (EU) 4th Framework Program (FWP) TEPSS Project [1]. The SBWR/ESBWR containments are represented in the PANDA facility by six cylindrical vessels and four condensers immersed in four water pools. In the EU 4th FWP IPSS project, in the PANDA facility have been performed investigations related to the Building Condenser of the SWR1000 (AREVA design) [2]. With the OECD/ISP42 program, a specific test consisting of six phases has been performed and analyzed in the PANDA facility to study the PCCS performance in very challenging situations. In the EU 5th FWP TEMPEST project, experimental investigations in the PANDA facility focused on the effects of noncondensable light gas (as hydrogen) on the PCCS performance [3], and, in the EU 5th FWP NACUSP project, the investigations in the PANDA facility focused on the natural circulation and stability of BWRs [4]. The part of investigations of the OECD/SETH project which were performed in the PANDA facility has dealt with separate effect tests addressing phenomena such as gas mixing, transport, stratification, and condensation relevant to LWR containment integrity [5-9]. The investigations performed in the PANDA facility within the OECD/SETH-2 project dealt with phenomena leading to the breakup of gas stratification in a LWR containment [10] by different means (basic phenomena, such as plumes and jets, or activation of component systems, e.g., spray, cooler, recombiner). 
TABLE 1: PANDA programs.

\begin{tabular}{|c|c|}
\hline Program & Investigations \\
\hline $\begin{array}{l}\text { 1991-1995 } \\
\text { EPRI/GE }\end{array}$ & Investigation of passive decay heat removal systems for SBWR \\
\hline $\begin{array}{l}\text { 1996-1998 } \\
\text { EU-4th FWP }\end{array}$ & Passive decay heat removal system tests for SWR1000 (IPPS project) and ESBWR (TEPSS Project) \\
\hline $\begin{array}{l}\text { 1998-2002 } \\
\text { OECD/ISP-42 }\end{array}$ & $\begin{array}{l}\text { Passive containment cooling system (PCCS) performance in very challenging situations represented in six different } \\
\text { phases }\end{array}$ \\
\hline $\begin{array}{l}\text { 1999-2004 } \\
\text { EU-5th FWP }\end{array}$ & $\begin{array}{l}\text { Effect of hydrogen distribution on passive systems (TEMPEST project) and Investigation of BWR-natural circulation } \\
\text { stability (NACUSP Project) }\end{array}$ \\
\hline $\begin{array}{l}\text { 2002-2006 } \\
\text { OECD/NEA }\end{array}$ & Gas mixing and distribution in LWR containments (SETH project): separate effects \\
\hline $\begin{array}{l}\text { 2007-2010 } \\
\text { OECD/NEA }\end{array}$ & Resolving LWR containment key computational issues (SETH-II project): separate effects, components, and systems \\
\hline $\begin{array}{l}\text { 2010-2013 } \\
\text { EU-7th FWP }\end{array}$ & Containment thermal-hydraulics of current and future LWRs for severe accident management (ERCOSAM project) \\
\hline
\end{tabular}

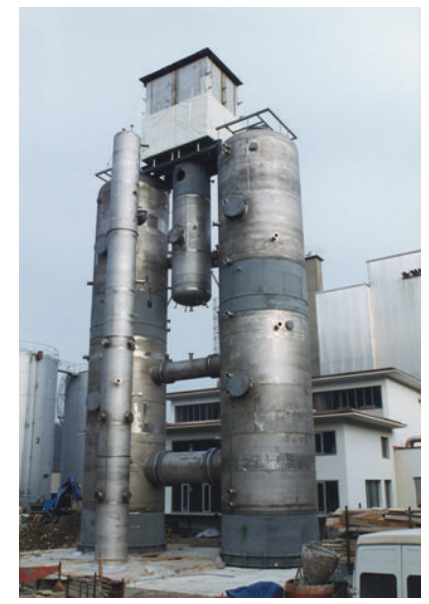

(a) Construction phase

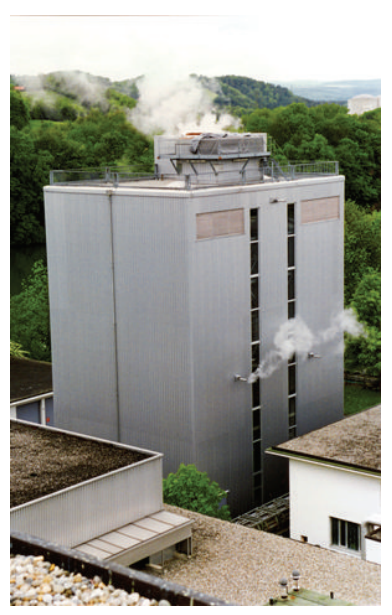

(b) During a test

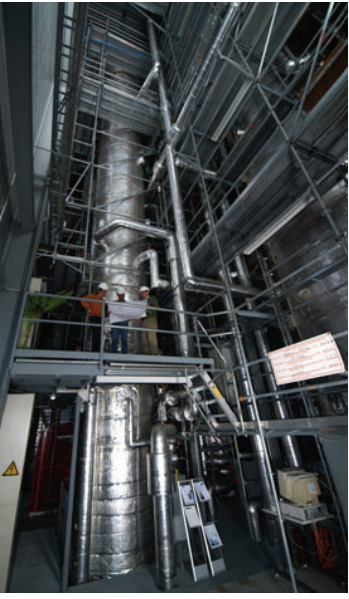

(c) Internal view

Figure 1: PANDA facility.

The EU 7th FWP ERCOSAM is an ongoing project cooperating with ROSATOM project SAMARA and is designed to investigate containment thermal-hydraulics of current and future LWRs for severe accident management [11].

The project aims at elaborating the effect of scaling on the phenomena evolution (e.g., gas transport, stratification, stratification breakup, condensation, convection, etc.) investigated in various experimental facilities (PANDA, MISTRA, TOSQAN, and KMS-like) of different scales.

The present paper provides an overview of the PANDA facility program results and some planned activities for incoming projects. The focus is in the investigations related to BWR and PWR containment systems. The PANDA facility investigations related to separate effect tests are just mentioned in this paper (Section 3.7).

\section{PANDA in Figures}

In Table 2, PANDA facility specifications are shown. It should be pointed out that upgrading PANDA instrumentation is a continuous process. The main criterion behind the effort to improve the facility instrumentation is to meet the requirements specified in the various PANDA test campaigns.

\section{PANDA Programs}

3.1. Simplified Boiling Water Reactor (SBWR). In the SBWR, passive containment condensers (PCCs) are positioned in water pools on top of the containment building. After the depressurization of the reactor pressure vessel (RPV) to the drywell (DW), a steam/nitrogen mixture flows to the PCCs, which are permanently connected to the containment without any control devices. Steam condensing in the PCCs heats the pools, which are open to the atmosphere, and gradually evaporate the pool water inventory (3-day capacity). The primary side condensate returns via make-up water tanks, that is, the Gravity Driven Cooling System (GDCS) to the RPV, and the nitrogen is purged to the suppression chamber (SC) gas space. The volume, temperature, and gas 
ESBWR versus PANDA
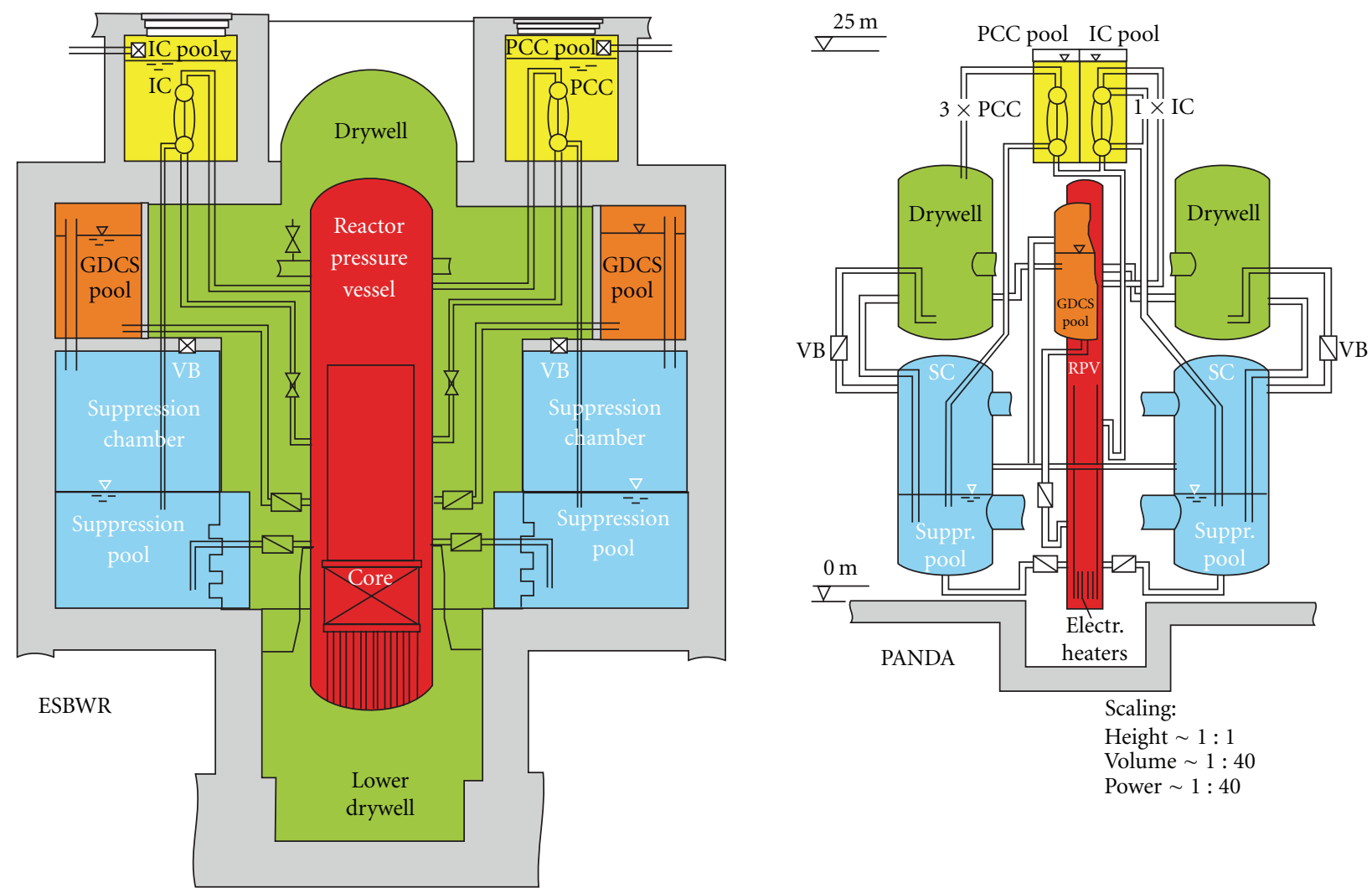

FIGURE 2: Schematic representation of ESBWR containment and PANDA.

TABLE 2: PANDA in figures.

\begin{tabular}{ll}
\hline $\begin{array}{l}\text { Operating specification } \\
\text { for the pressure vessels }\end{array}$ & Up to 10 bar $/ 200^{\circ} \mathrm{C}$ fluid conditions \\
\hline Power & $1.5 \mathrm{MW}$ electric heat power \\
\hline Total volume & $\begin{array}{l}515 \mathrm{~m}^{3} \text { (modular structure based on } 6 \\
\text { main vessels) }\end{array}$ \\
\hline Total height & $25 \mathrm{~m}$ \\
\hline Instrumentation & $\sim 1000$ sensors (temperature, pressure, \\
& $\begin{array}{l}\text { flow rate, levels, etc.) } \\
\text { PIV (Particle Image Velocimetry (2D } \\
\text { velocity fields) } \\
\text { Mass spectrometer (air, steam, and } \\
\text { helium gas concentration) }\end{array}$ \\
\hline & $\begin{array}{l}\text { Hierarchical programmable logic control } \\
\text { system } \\
\text { Graphical-display man-machine } \\
\text { interface with process visualization and } \\
\text { online/offline trending }\end{array}$ \\
\hline
\end{tabular}

inventory of this gas space determine the pressure level for the containment system [12].

PANDA was configured as a thermal-hydraulic model of the SBWR containment and passive decay heat removal system; power, volumes, horizontal areas, and flow rates were scaled with the system scale of $1: 25$, while relevant elevations, pressures, and pressure drops were scaled 1:1 [13]. Yadigaroglu's (1996) scaling study included also the identification of any distortions in the representation of phenomena and the manner in which this distortion could be considered when the experimental data are used for computer code qualification.

The PANDA transient system tests performed for the SBWR concept demonstrated very favourable and robust overall containment behaviour, even under extreme boundary conditions [14].

Figure 3 shows the PCC behaviour in terms of active/ inactive area for heat transfer. The term "active" is used to indicate the absence of air inside the PCC tubes and presence of water from the secondary side. The air is a noncondensable gas which deteriorates the heat transfer. At the beginning of a postulated LOCA, the PCC tubes are fully immersed in the water pool. The steam generated in the RPV is transferred into the DW and from there to the PCC where a part condenses and returns into the RPV and a part is vented to the WW pool where it condenses. During this initial phase, the air present in the DW and PCC tubes is vented into the wetwell (WW) [15], so all the active tube length (red in Figure 3) is available for heat transfer, leading to the steam condensation. As the transient continue, further and the decay heat decreases, the PCCs have an overcapacity and 


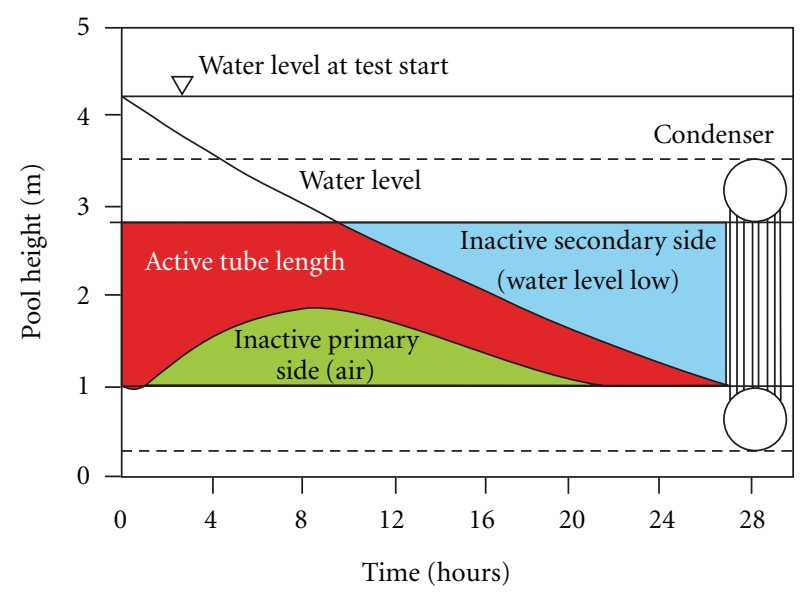

Figure 3: Schematic representation of PCC active area for heat transfer during a transient.

the pressure in the DW decreases below the WW pressure. In this situation, the vacuum breakers (between drywell and wetwell) open, and a steam-air gas mixture is transported back to the DW.

The air transported back to the DW will flow in the PCC tubes where it accumulates in the lower part of the tubes (green area in Figure 3). Because of the presence of air, the lower part of the PCC tubes becomes "inactive." The inactive area increases because the decreasing decay heat produces less steam than the nominal condensing capacity, and air is not any more vented to the WW but accumulates in the lower part of the tubes. The PCC "automatically adjusts" it power with noncondensable gas. After some time $(\sim 9$ hours in Figure 2) due to boiling of the PCC pools the water level decreases and consequently the "active area" of the tube (from the pool side) is decreased. To compensate the diminished active areas from pool side, the air inside the tube is gradually vented to the WW.

\subsection{Economic Simplified Boiling Water Reactor (ESBWR). A} schematic representation of ESBWR containment in PANDA is shown in Figure 2. (It should be pointed out that the ESBWR-PANDA containment arrangement in Figure 2 corresponds to an earlier design of the ESBWR (4000 MWt) where the GDCS gas space was connected to the WW gas space. In the present ESBWR (4500 MWt) design, the GDCS pool is open to the drywell as in the original SBWR, and the condensate return line of the PCC is connected to the GDCS pool.) The two green vessels are interconnected by a large diameter pipe (IP) (the IP is not shown in Figure 2) and represent the DW; the blue vessels represent the WW (in PANDA these two vessels are interconnected by two large diameter pipes: one in the water pool space, and one in the gas space). The red vessel represents the reactor pressure vessel (RPV), whereas the brown vessel represents the gravity driven cooling system (GDCS) tank. The yellow pool and condensers represent the pool of the passive cooling condensers (PCCs) and the isolation condenser (IC). The ESBWR utilizes basically the same passive containment cooling system as the SBWR. However, the make-up water tanks are completely separated from the DW and connected to the SC gas space. This provides, after draining of the makeup water tanks, more volume for the noncondensable gases which are purged from the DW via the PCCs to the SC. The SC pressure increase and ultimately the containment pressure are lower than in a SBWR configuration with identical dimensions. The condensate from the PCCs is directly routed to the RPV. The ESBWR containment is represented in PANDA at about $1: 40$ system scale [16]. The PANDA tests with the ESBWR configuration are similar to the SBWR tests but extend into areas not fully explored before. Some of the investigations were also devoted to the possible degradation of the PCCS performance in postulated severe accident scenarios with hydrogen release due to the fuel cladding metal-water reaction. Helium was used to simulate hydrogen. Other tests covered the deferred release of air which had supposedly been "trapped" in the DW, low water level in the PCC pools, startup, and system interaction. Generally speaking, the conclusions of the SBWR series test were confirmed. Figure 4 shows as example the containment pressure during a long transient (28 hours) and the decrease of water level in pools of the PCCs (during the transient the release of light gas hydrogen was not simulated). As can be noted, the pressure remains nearly constant until when the water level in the pool reaches nearly the elevation corresponding to the PCC lower drum.

Figure 5, related to PANDA Test T1.2, shows the system pressure during the evolution of PANDA test in which helium (used to simulate hydrogen) was also released.

The initial conditions for Test T1.2 (temperatures, pressures, partial pressures, and water levels) were based on the transient status predicted for the ESBWR at one hour after scram in the course of a MSLB LOCA. At this time, the RPV has been depressurized, and the actual containment pressure is about 2.5 bar. Test T1.2 addresses a core overheat and release of hydrogen. The Test T1.2 allowed for investigating gas stratification and retention in dead-end containment volumes (the "stand-by" volume) and the effect of light gas (helium) on the overall system behavior.

The Test T1.2 included three main phases: in Phase 1 (up to $10000 \mathrm{~s}$ ) was simulated the release in the drywell of steam (i.e., the normal PCCS containment heat removal mode), in Phase 2 (10000s to $17200 \mathrm{~s}$ ), the release of hydrogen and steam (simulating the zircaloy oxidation), and then in Phase 3 (17200s to $42000 \mathrm{~s}$ ) again only the release of steam.

The quantity of helium injected in the test was scaled by assessing the amount of hydrogen that would be generated by assuming $100 \%$ cladding $\mathrm{M}-\mathrm{W}$ reaction in an ESBWR core with 1132 fuel bundles and by considering a 1/40-volume scale of PANDA. It should be pointed out that the timing for steam or helium release does not correspond to any specific severe accident scenarios. Figure 5 shows the RPV pressure (sensor identified by MP.RP1), DW pressure (sensor identified by MP.D1), and WW pressure (sensor identified by MP.S1).

In the early stage of the accident, the noncondensable gases initially filling the DW are purged through the Main Vent (MV) lines and the PCC vent lines to the WW. The DW to WW pressure difference can vary only within a small range 


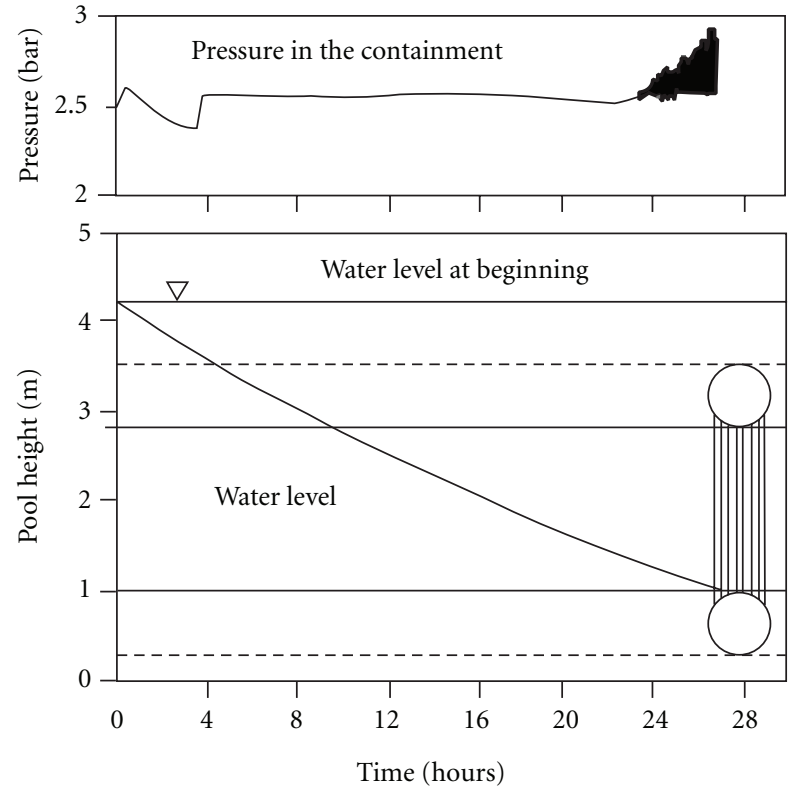

Figure 4: Pressure in the containment (above) as function of water level in the PCC pools.

given by the hydrostatic head of the vent line submergence in the pressure suppression pool. Venting of noncondensable gases from the DW to the WW causes a shift of both pressures to higher values due to a WW pressure increase.

For the first $1000 \mathrm{~s}$ into the tests, the PCCs were slightly overloaded; therefore, the pressure in the system slightly increased (by about 0.1 bar). In accordance with the decreasing decay heat power generated in the RPV, the steam rate released from the RPV to the DW vessels decreased with time. Therefore, about $1000 \mathrm{~s}$ after test started, the PCC units were able to condense all the steam and the pressure in the DW reached its maximum during Phase 1 . For $t>1000 \mathrm{~s}$ the pressure started to slightly decrease until the start of helium injection.

The release of helium caused a sudden increase in DW pressure. The increase continued also when the injection of helium was stopped because after release of non condensable gas was completed, it took some additional time until the stratification process in the DW reached a steady state, and most of the helium was vented to the WW. The highest pressure in the DW was around 5.7 bar and was reached at about $20000 \mathrm{~s}$. Then, until the end of the transient, the pressure remained nearly constant, that is, a new equilibrium was reached by the heat generated in the RPV (energy source) and the energy extracted by the PCCS [17].

3.3. SWR-1000 with Building Condenser. The SWR-1000 BWR design passively transfers decay heat from the RPV to core flooding pools, which are located in the upper part of the DW and gradually start heating the DW with steam. Containment cooling condensers installed above the core flooding pools condense steam from the gaseous mixture present within the DW. Schematically how the SWR-1000 building condenser is represented in PANDA is shown in

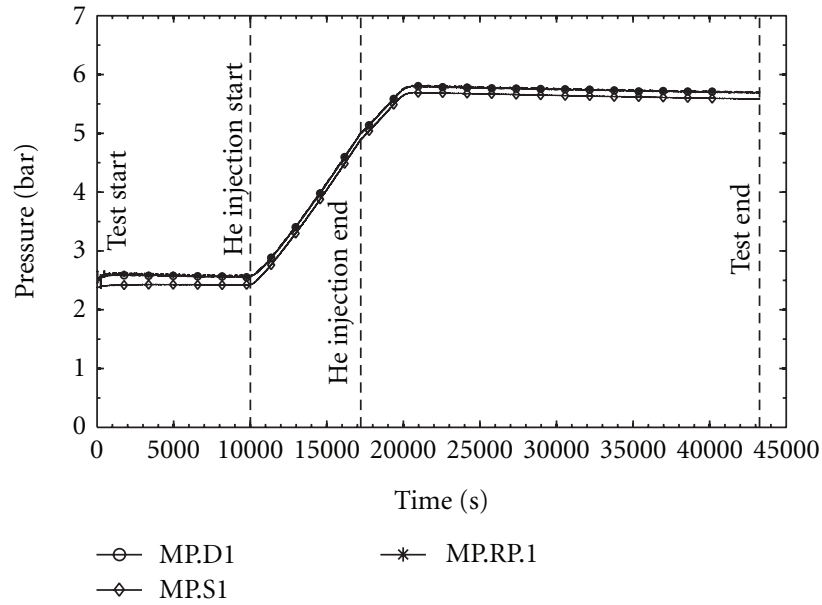

Figure 5: RPV, DW, and WW pressure curves.

Figure 6. These condensers consist of inclined finned tube. The low and high ends of their secondary sides are connected to the bottom and to the higher level of the dryer/separator storage pool, which is situated on top of the containment. The containment cooling condenser system of the SWR-1000 is represented in PANDA at about $1: 26$ scale, except for the dryer/separator storage pool, which is much smaller, leading to a time compression factor of about 8 for the transient system tests. Different types of tests were performed, based on different small, medium, and large-break LOCAs with and without core degradation, in the former case with helium injected to simulate the release of hydrogen. The test series as a whole identified important containment phenomena and successfully demonstrated the robustness of the SWR-1000 containment-cooling system [2].

3.4. Natural Circulation and Stability of BWRs. Figure 7 shows the facility configuration for natural circulation and stability of BWR investigations in PANDA. In this program only part of the facility was used (i.e., mainly the RPV and the IC). The investigations address the flashing-induced instability which could occur at low pressure and low power (e.g., during startup and shutdown). In the tests, the water flowed down from the downcomer then was heated up in the riser.

The water column in the riser during the test was in the order of $11 \mathrm{~m}$, so the overhead pressure for the water was $\sim 1.1$ bar. The coolant at the bottom of the riser was subcooled and becomes super-heated while flowing in the riser (i.e., due to the decrease of pressure and of the saturation temperature (red curve in Figure 8) caused by the lower water column head) and consequently vaporize (flash).

Additionally, Figure 8 shows the temperature profiles measured along the RPV vertical central axis (black). The water flashes at around $8 \mathrm{~m}$.

Figure 9 shows, as an example, the velocity measured in the downcomer during a test. The flow oscillations were analyzed for all the different tests, and the detailed results and analysis were reported in [4]. 


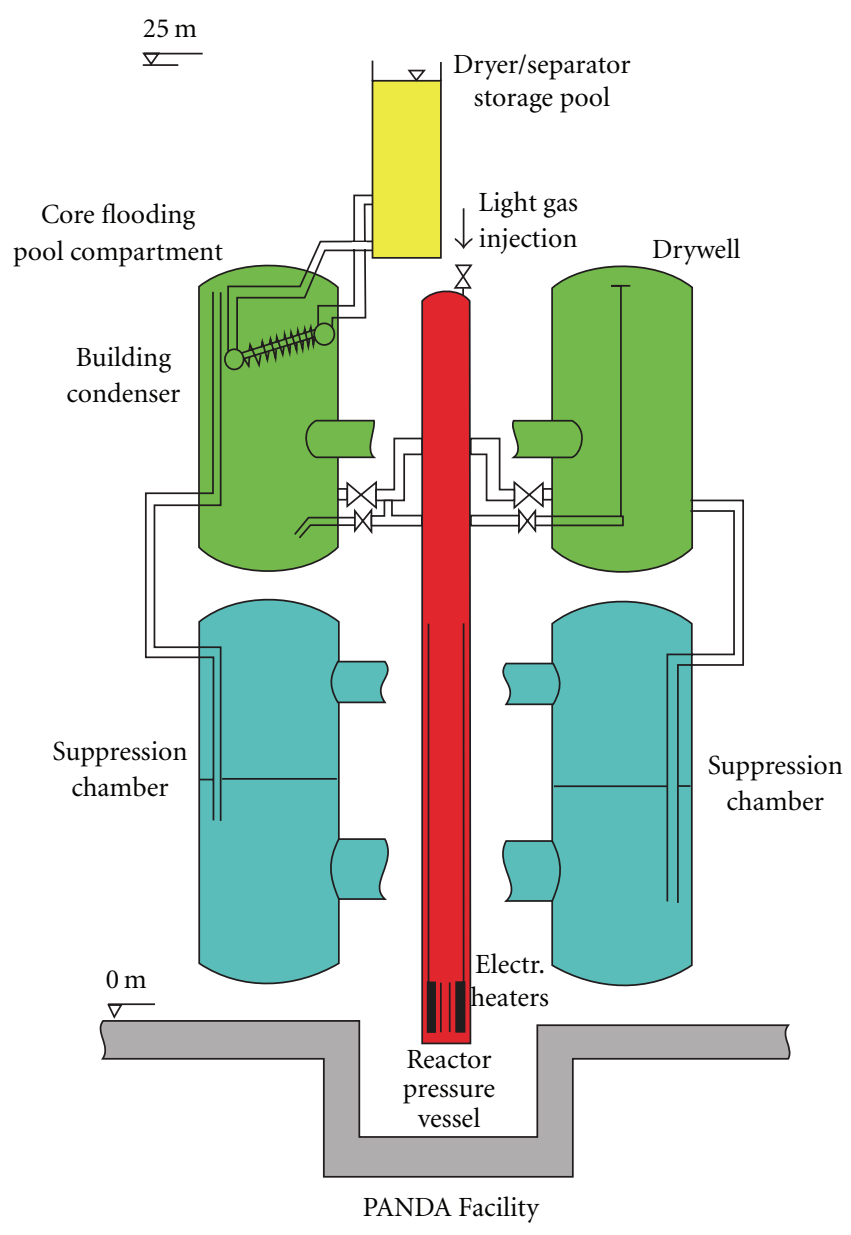

FIGURE 6: In the PANDA test facility is represented the SWR-1000 building condenser.

3.5. Investigations Related to PWR Systems. PANDA has been used for investigations related to PWR in the recent OECD/ SETH-2 project and in the ongoing ERCOSAM project (Table 1).

In these two projects, in relation to PWR, the investigations dealt with safety component tests and with containment system tests. The component tests addressed the effect of activation of containment cooler [18, 19], sprays [19], or recombiners on the containment atmosphere, particularly on the hydrogen concentration.

PWR containment system investigations in PANDA were performed with respect to the opening hatched series. These tests addressed the issue of gas distribution in two large volumes (Figure 10, vessels 1-2 form the first volume, vessels 3-4 form the second volume), having different gas concentrations and at different pressures when they are suddenly interconnected. This situation occurs in the case of the sudden opening of a rupture disk and could be directly related to the EPR ${ }^{\mathrm{TM}}$ design. Data on the mixing of fluids of different density in two adjacent vessels as the result of the sudden opening of an aperture are rather scarce and do not encompass data at large-scale facilities.

Gas transport, mixing, and distribution within the containment compartments is driven by the pressure difference

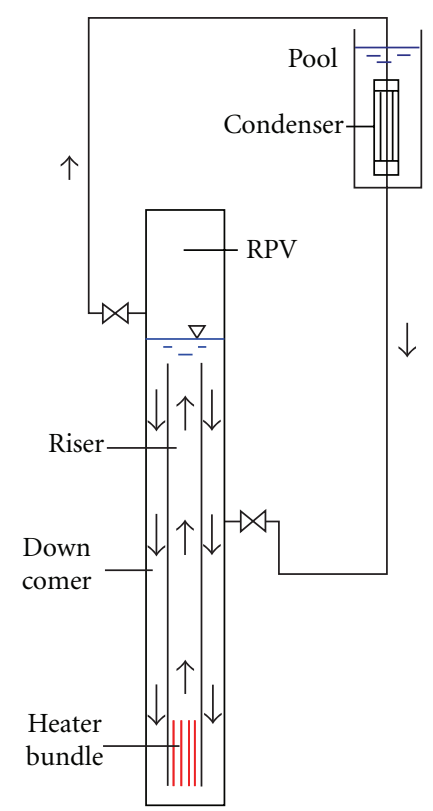

FIgURe 7: Configuration of PANDA RPV and pool condenser.

between the two large volumes in the early phase of the test and by temperature gradient and gas mixture concentration differences after the pressure between the vessels has been equalized [20].

3.6. Other Foreseen PANDA Application to PWR. Advanced PWR containments are designed with a large number of compartments and safety systems. For example, the EPR ${ }^{\mathrm{TM}}$ is designed with a containment which includes about 140 compartments or rooms and different types of active and passive safety systems (e.g., spray, recombiners, rupture disks, core catcher, etc.) [21]. From a conceptual point of view, such type of containment is constituted of two main volumes or "compartments": one "inner compartment", in which components of the primary circuit (reactor pressure vessel, steam generator, pressurizer, pumps, etc.) are located and one "external compartment" where other components and systems are located. Safety components, for example, recombiner are located in both volumes, while the spray system rings are located in the dome of the external volume. Rupture foils and convection foils are positioned in the upper regions above the steam generator mixing dampers are positioned in the lower region, that is, above the incontainment refuelling water storage tank (IRWST). Rupture foils and convection foils break when the pressure difference between the inner and external compartments exceeds around 50 mbar (convection foils will open if temperature is higher than $80-85^{\circ} \mathrm{C}$ ), while the mixing dampers open for a pressure difference of around $35 \mathrm{mbar}$ (for pressure above 1.2 bar).

Therefore, during postulated accident sequences with release of steam (and later also hydrogen), the inner compartment would be pressurized, rupture, and convection foils and mixing dampers would open, and steam air hydrogen would flow from the inner to the external compartment. 


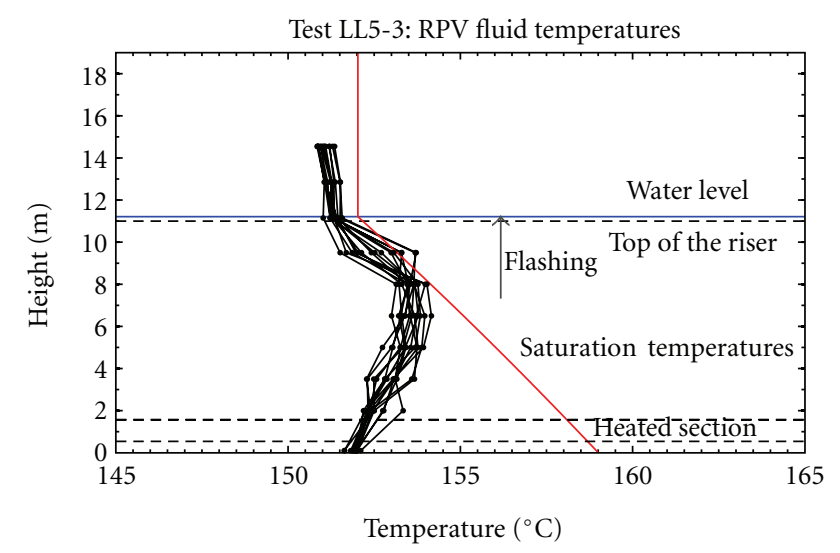

FIGURE 8: Fluid temperature profiles measured along RPV central axis indicate flashing in the upper riser region.

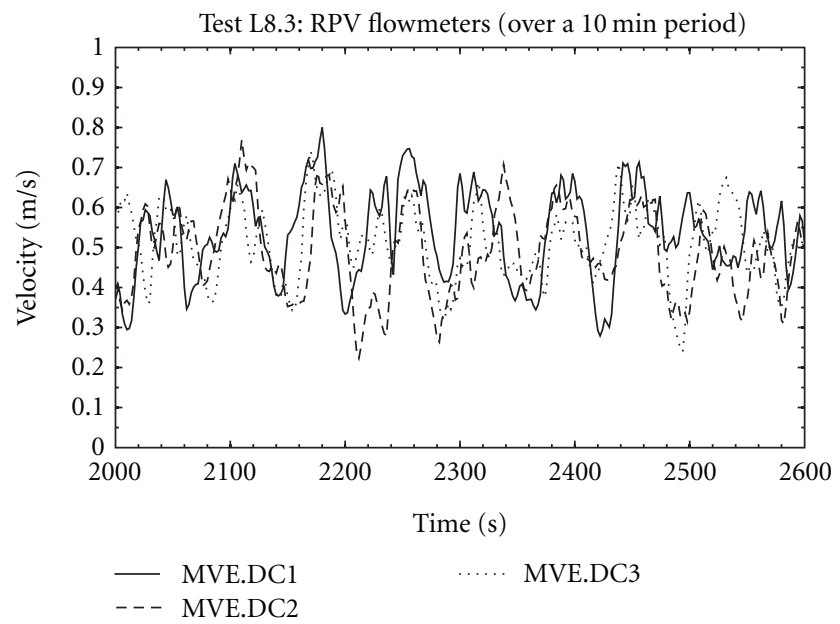

FIgURE 9: One-component velocity in the downcomer.

Spray activation would reduce the system pressure by inducing condensation and will also enhance atmospheric mixing. The condensed water would flow down and accumulate in the IRWST, while gas (steam air hydrogen) flow could establish a natural circulation loop. The mixture distribution in the containment will depend on the number of rupture and convection foil openings and by the mixing dampers (Figure 11, left). With respect to PWR system, the topic proposed to investigate is the interaction between the natural circulation flow within containment compartments (inner and external compartments) and the convection flow induced by safety systems activation. PANDA tests addressing the discussed scenarios are proposed.

Figure 11 shows, on the left, a schematic representation of the main $\mathrm{EPR}^{\mathrm{TM}}$ containment compartments and, on the right, the respective compartments in PANDA. The inner compartment (margins made with brown-dotted lines) including the IRWST is represented mainly by the lower two vessels and the lines R31-R42 (the volume ratios in PANDA between external and internal regions are not in scale with $\mathrm{EPR}^{\mathrm{TM}}$ ). The external compartment is represented by the upper two vessels and by downcomers DC1, D13, and DC2 and D24. The spray nozzle is installed in the external volume

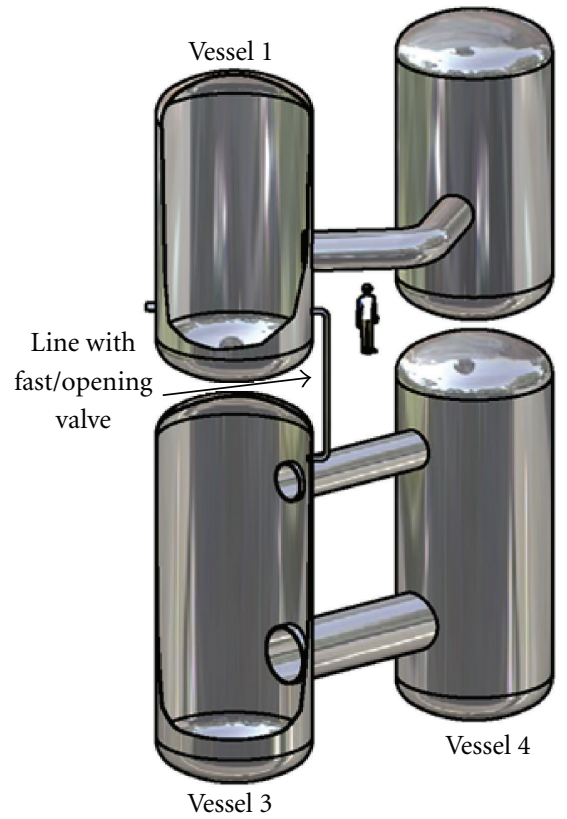

FIGURE 10: Schematic for the rupture disk tests.

and the heat source in the Drywell downcomers 1 and 2. In Figure 11 (left side), the rupture foils (green rectangles) and convection foils (magenta) are located in the upper regions. In PANDA (Figure 11 right), these are represented with the same color (magenta). The mixing dampers are located in the lower region above the IRWST (gold color). These PANDA investigations have been proposed in the frame of a new OECD/NEA project named HYMERES [22]. It should be pointed out that the main heights and volumes of $\mathrm{EPR}^{\mathrm{TM}}$ and PANDA are not to scale; therefore the results for PANDA investigations cannot directly be extrapolated to the $\mathrm{EPR}^{\mathrm{TM}}$. The main aim with these investigations is the creation of a database at large scale, for code assessment and validation purposes.

3.7. Separate Effect Tests. In PANDA, separate tests were performed for a broad range of conditions in the frame of the OECD/SETH and SETH-2 projects. The main objective of these tests was to generate an experimental database of containment code validations.

The OECD/SETH PANDA investigations included three series of tests characterized by wall plumes, free plumes, and horizontal high-momentum jets. In addition to these series of tests, one specific three-gas test, identified in the SETH-1 project as Test 25, with air, steam, and helium has been carried out.

The OECD/SETH-2 PANDA separate effect investigations included vertical fluid release (jet or plume series $[23,24]$ and horizontal fluid release series [25].

The description of the PANDA SETH and SETH-2 experimental results goes beyond the scope of the present paper and therefore will be omitted. 

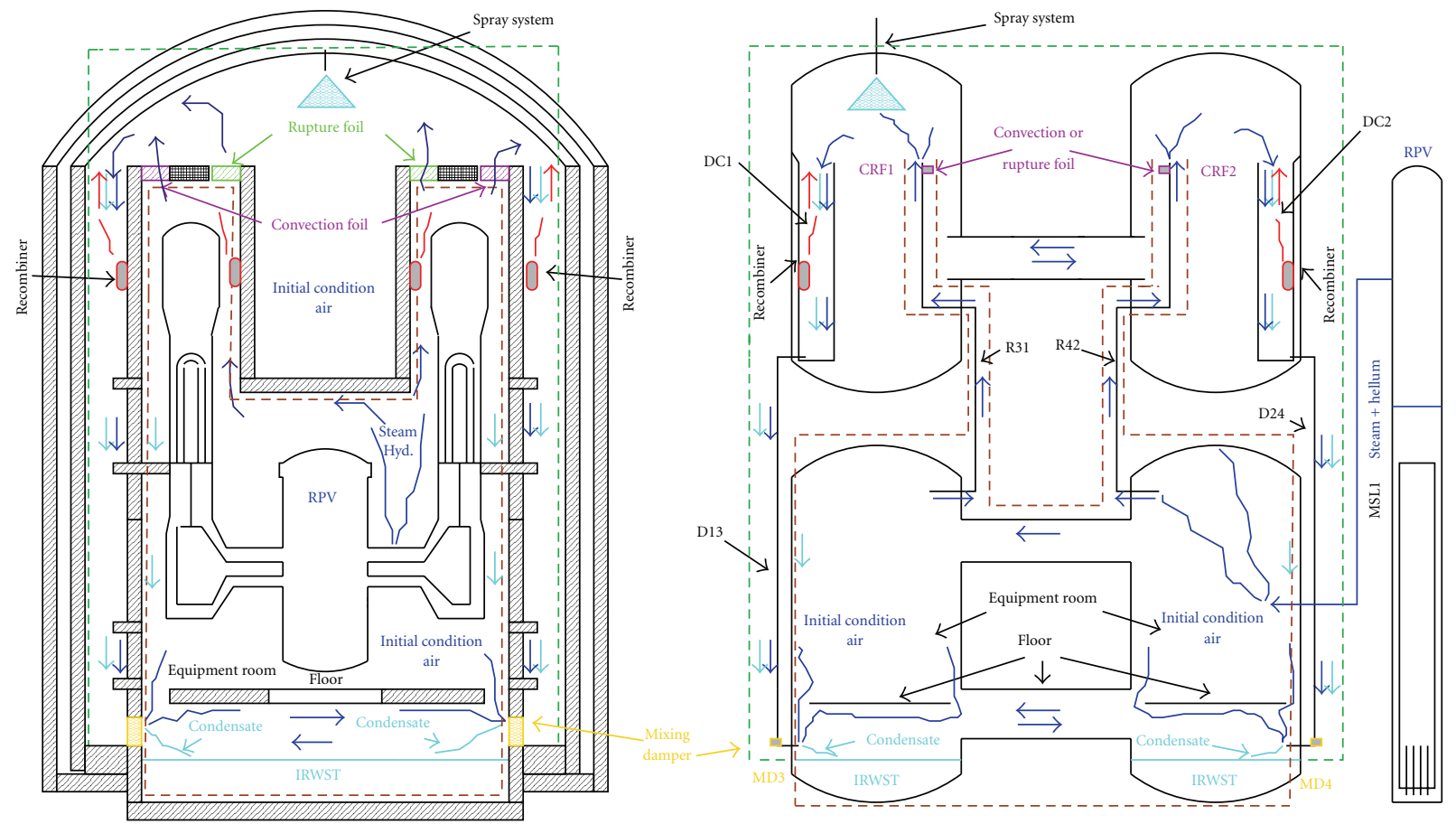

FIGURE 11: Schematic of PANDA facility versus EPR ${ }^{\mathrm{TM}}$ containment (height and main volumes are not in scale).

\section{Conclusion}

The paper provides an overview of the research programs performed and ongoing in the PANDA facility. The facility is well suited to investigate the safety system of several Generation III+ type reactors. The experimental results obtained are unique. Some of the tests related to the SBWR went through an audit from the NRC and are used as reference for the PCCS performance and for the certification of the ESBWR by the US NRC. Also, the tests related to the SWR1000 provided experimental data on the system behaviour under a variety of accident scenarios. PANDA was used in the framework of several European and OECD projects and has allowed the generation of large experimental database which were used to develop and validate CFD and safety analysis codes. The planned investigations of EPR ${ }^{\mathrm{TM}}$ type systems will further provide the experimental database at large scale on flow circulation between containment compartments and with the activation of safety systems. These results will not be directly extrapolated to $\mathrm{EPR}^{\mathrm{TM}}$ but will be used for assessing and validating computational tools to the PANDA scale, before their use for the real reactors.

\section{References}

[1] M. Huggenberger, C. Aubert, T. Bandurski et al., "ESBWR related passive decay heat removal tests in PANDA," in Proceedings of the 7th International Conference on Nuclear Engineering (ICONE '99), Tokyo, Japan, 1999.

[2] J. Dreier, C. Aubert, M. Huggenberger, H. J. Strassberger, J. Meseth, and G. Yadigaroglu, "The PANDA Tests for the SWR1000 passive containment cooling system," in Proceedings of the 7th International Conference on Nuclear Engineering (ICONE '99), Tokyo, Japan, 1999.

[3] D. Paladino, O. Auban, M. Huggenberger, and M. Andreani, "Investigation of light gas effects on passive containment cooling system in ALWR," in Proceedings of the 10th International Topical Meeting on Nuclear Reactor Thermal Hydraulics (NURETH '03), Seoul, Korea, 2003.

[4] O. Auban, D. Paladino, and R. Zboray, "Experimental investigation of natural-circulation flow behavior under lowpower/low-pressure conditions in the large-scale panda facility," Nuclear Technology, vol. 148, no. 3, pp. 294-312, 2004.

[5] O. Auban, R. Zboray, and D. Paladino, "Investigation of large-scale gas mixing and stratification phenomena related to LWR containment studies in the PANDA facility," Nuclear Engineering and Design, vol. 237, no. 4, pp. 409-419, 2007.

[6] D. Paladino, R. Zboray, P. Benz, and M. Andreani, “Three-gas mixture plume inducing mixing and stratification in a multicompartment containment," Nuclear Engineering and Design, vol. 240, no. 2, pp. 210-220, 2010.

[7] D. Paladino, R. Zboray, and O. Auban, "The panda tests 9 and 9bis investigating gas mixing and stratification triggered by low momentum plumes," Nuclear Engineering and Design, vol. 240, no. 5, pp. 1262-1270, 2010.

[8] D. Paladino, R. Zboray, M. Andreani, and J. Dreier, "Flow transport and mixing induced by horizontal jets impinging on a vertical wall of the multi-compartment PANDA facility," Nuclear Engineering and Design, vol. 240, no. 8, pp. 2054-2065, 2010.

[9] R. Zboray and D. Paladino, "Experiments on basic thermalhydraulic phenomena relevant for LWR containments: gas mixing and transport induced by buoyant jets in a multicompartment geometry," Nuclear Engineering and Design, vol. 240, no. 10, pp. 3158-3169, 2010. 
[10] D. Paladino, M. Huggenberger, M. Andreani et al., "LWR containment safety research in PANDA," in Proceedings of the International Conference on Advances in Nuclear Power Plants (ICAPP '08), pp. 1853-1861, Anaheim, Calif, USA, June 2008.

[11] ERCOSAM: containment Thermal-hydraulics of current and future LWRs for severe accident management, SP5-Euratom, Collaborative Project, Small or medium-scale focused research project, FP7-Fission-2009, Grant Agreement No 249691, 2010.

[12] B. S. Shiralkar, M. D. Alamgir, and J. G. M. Andersen, "Thermal hydraulic aspects of the SBWR design," Nuclear Engineering and Design, vol. 144, no. 2, pp. 213-222, 1993.

[13] G. Yadigaroglu, "Derivation of general scaling criteria for BWR containment tests," in Proceedings of the 4th International Conference on Nuclear Engineering (ICONE '96), pp. 547-558, New Orleans, La, USA, March 1996.

[14] G. Yadigaroglu, J. Dreier, and M. Huggenberger, "The PANDA tests for the SBWR," in Proceedings of the 25th Water Reactor Safety Information Meeting, Bethesda, Md, USA, October 1997.

[15] T. Bandurski, M. Huggenberger, J. Dreier et al., "Influence of the distribution of noncondensibles on passive containment condenser performance in PANDA," Nuclear Engineering and Design, vol. 204, no. 1-3, pp. 285-298, 2001.

[16] H. W. Schenck and A. M. Hoft van Huysduynen, "Scaling analysis of passive containment cooling tests," INNO-TEPSS (96)-DO04. ECN, Petten, Nederland, 1997.

[17] D. Paladino, O. Auban, M. Huggenberger, and J. Dreier, "A PANDA integral test on the effect of light gas on a Passive Containment Cooling System (PCCS)," Nuclear Engineering and Design, vol. 241, no. 11, pp. 4551-4561, 2011.

[18] G. Mignot, R. Kapulla, N. Erkan, R. Zboray, and D. Paladino, "Containment cooler performance in the presence of light non condensable gas with cooler location as a primary parameter," in Proceedings of the 14th International Topical Meeting on Nuclear Reactor Thermalhydraulics, Toronto, Canada, September 2011.

[19] N. Erkan, R. Kapulla, G. Mignot, R. Zboray, and D. Paladino, "Experimental investigation of spray induced gas stratification break-up and mixing in two interconnected vessels," Nuclear Engineering and Design, vol. 241, no. 9, pp. 3935-3944, 2011.

[20] D. Paladino, G. Mignot, N. Erkan, R. Zboray, R. Kapulla, and M. Andreani, "Sudden discharge of gas mixture in a confined multi-compartment," in Proceedings of the 14th International Topical Meeting on Nuclear Reactor Thermalhydraulics (NURETH '10), Toronto, Canada, September 2011.

[21] R. P. Martin, C. A. Bonilla, and E. S. Williams, "Combustible gas control system evaluation for the U.S. EPR," in Proceedings of the 13th International Topical Meeting on Nuclear Reactor Thermal Hydraulics (NURETH '09), Kanazawa city, Ishikawa Prefecture, Japan, September 2009.

[22] CSNI, Summary record of the Forty-ninth CSNI Meeting, NEA/SEN/SIN(2011)2, Paris, France, June 2011.

[23] R. Kapulla, D. Paladino, G. Mignot, R. Zboray, and S. Gupta, "Break-up of gas stratified in LWR containment induced by negatively buoyant jets and plumes," in Proceedings of the International Conference in Nuclear Engineering (ICONE '09), Brussels, Belgium, July 2009.

[24] G. Mignot, D. Paladino, R. Kapulla, and R. Zboray, "Overview of vertical fluid release series," in Proceedings of the 13th International Topical Meeting on Nuclear Reactor Thermal Hydraulics (NURETH '09), Kanazawa City, Ishikawa Prefecture, Japan, September 2009.
[25] R. Zboray, D. Paladino, G. Mignot, and R. Kapulla, "Mixing of density stratified containment atmosphere by horizontal jet release," in Proceedings of the International Conference Nuclear Energy for New Europe, Bled, Slovenia, September 2009. 

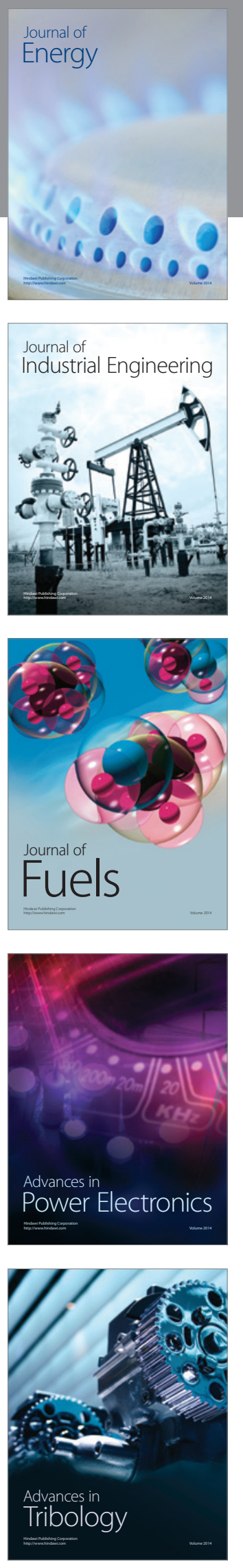
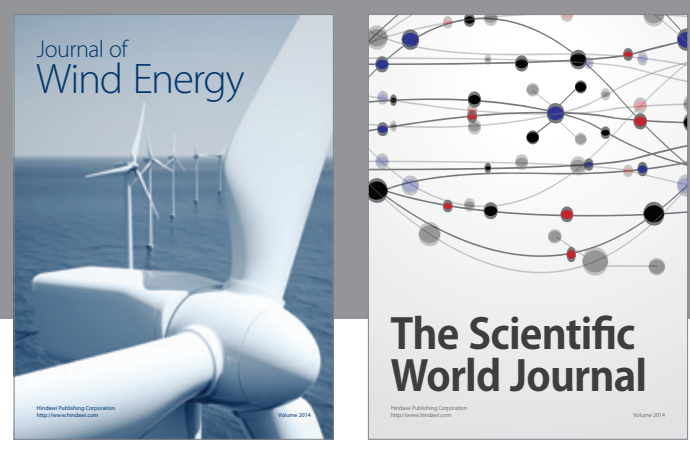

The Scientific World Journal

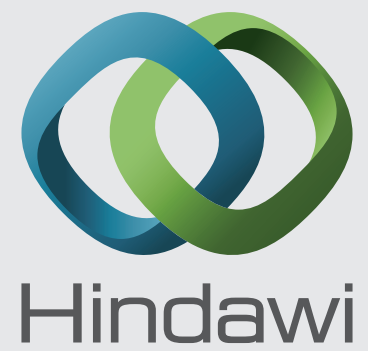

Submit your manuscripts at http://www.hindawi.com
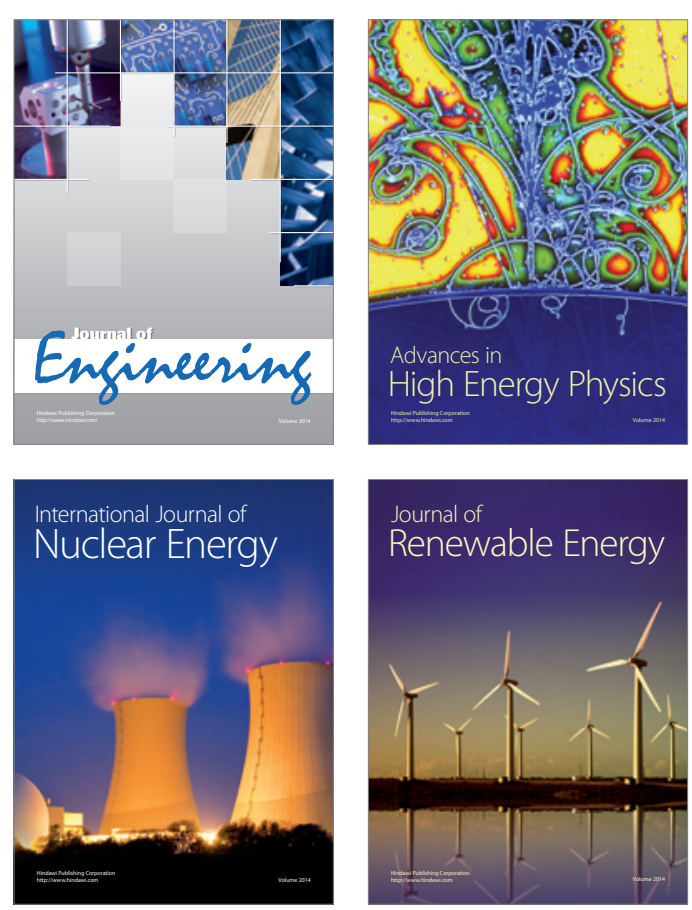

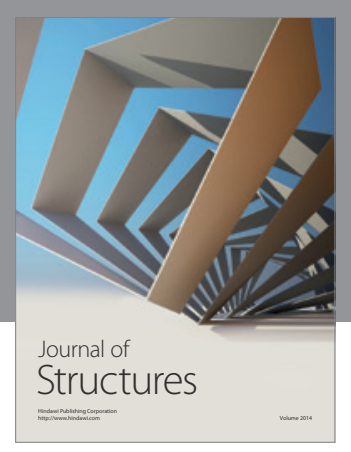

Rotating
Mechinery
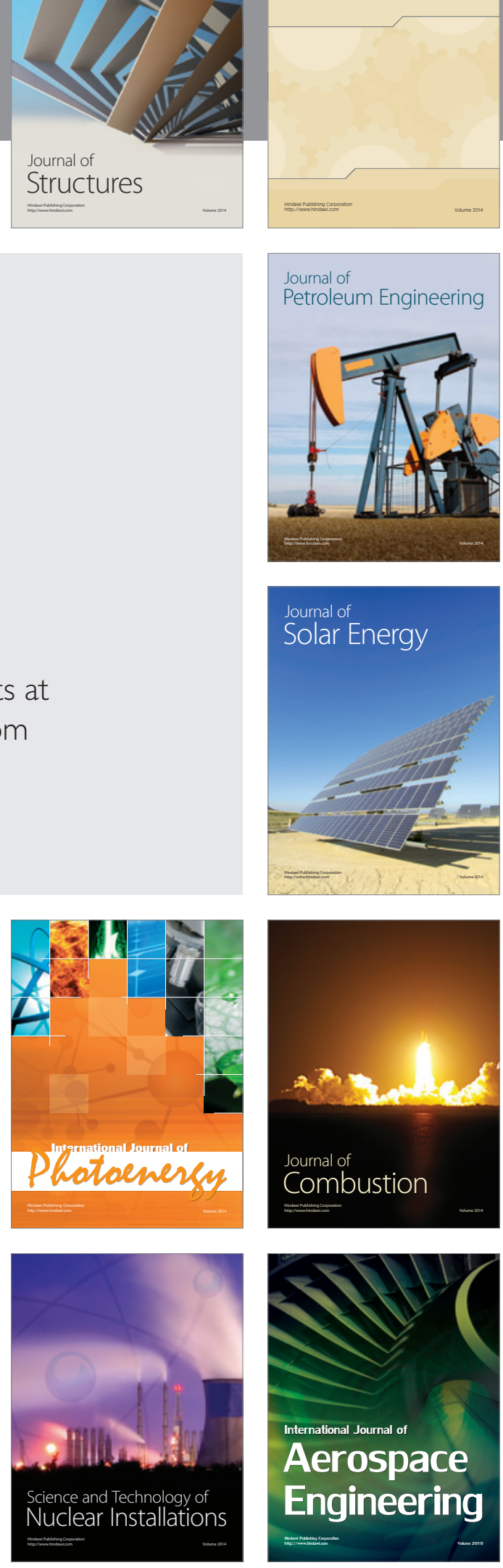